\title{
Characterisation of Precipitation Hardening Response and As-Quenched Microstructures in Al-Mg(-Ag) Alloys
}

\author{
Masahiro Kubota*, Jian Feng Nie and Barry Chales Muddle \\ School of Physics and Materials Engineering, PO Box 69M, Monash University, Victoria 3800, Australia
}

The age-hardening response in Al-Mg alloys, with and without trace additions of $\mathrm{Ag}$, aged isothermally at $160^{\circ} \mathrm{C}, 200^{\circ} \mathrm{C}$ and $240^{\circ} \mathrm{C}$ was investigated. Additionally, the effects on ageing response of cold work introduced after solution treatment, water quenching and prior to the ageing treatments were clarified for the Al-Mg- $(\mathrm{Ag})$ alloy. The dislocation populations in the as-quenched microstructures of $\mathrm{Al}-10 \mathrm{mass} \% \mathrm{Mg}$ alloys with and without trace additions of $\mathrm{Ag}$ were characterised. Trace additions ( $0.5 \mathrm{mass} \%)$ of $\mathrm{Ag}$ to $\mathrm{Al}-\mathrm{Mg}$ alloys with low solute $\mathrm{Mg}$ contents $(<5$ mass $\%)$ promote an age-hardening response, while similar additions to $\mathrm{Al}-\mathrm{Mg}$ alloys with higher solute $\mathrm{Mg}$ contents (e.g. 10 mass $\%$ ) enhance significantly the age-hardening response. The age-hardening response in an $\mathrm{Al}-10 \mathrm{Mg}-0.5 \mathrm{Ag}$ (mass \%) alloy is significantly enhanced by the introduction of $7 \%$ cold work, post solution treatment and prior to ageing at $160^{\circ} \mathrm{C}$ and $200^{\circ} \mathrm{C}$. The identity of the dislocations in as-quenched Ag-free and Ag-modified Al-10 mass $\% \mathrm{Mg}$ alloys has been confirmed as unit perfect $a / 2\langle 110\rangle$ type. The addition of Ag does not appear to modify the form of the dislocations and no dissociation of these dislocations was observed. The density of dislocations in the solution treated and quenched condition in the Al-10 mass $\% \mathrm{Mg}$ alloy was higher by a factor of 2 compared to that in the $\mathrm{Al}-10 \mathrm{Mg}-0.5 \mathrm{Ag}$ (mass $\%$ ) alloy subjected to similar treatment.

(Received May 7, 2004; Accepted July 27, 2004)

Keywords: precipitation hardening, aluminium-magnesium, aluminium-magnesium-silver, microstuctural characterisation, T6 treatment, T8 treatment

\section{Introduction}

It is well established that Al-Mg alloys achieve a combination of good mechanical properties and formability through solid solution strengthening, and Al-Mg alloys have thus found commercial use in cast and wrought forms for a variety of applications. ${ }^{1)}$ However, the recent consistent demand for a reduction in the weight of structural components, coupled with an increase in strength, has focused attention on the development of new structural aluminium alloys of high specific strength. There is apparently great potential for an age-hardening response in Al-Mg alloys according to the equilibrium phase diagram. ${ }^{2}$ However, when compared with other precipitation hardening aluminium alloys, such as those of the $\mathrm{Al}-\mathrm{Cu}$ system, alloys with solute contents in the range 7-10 mass \% Mg have been found to exhibit an abnormally low age-hardening response ${ }^{3)}$ and no significant age-hardening response has been detected in those alloys with less than 5 mass\% Mg. ${ }^{4}$

It is also well established that trace additions of $\mathrm{Ag}$ $(\sim 0.4$ mass $\%)$ stimulate precipitation behaviour in all $\mathrm{Al}$ alloys containing $\mathrm{Mg}$, with an acceleration in the kinetics of the age-hardening response and an increase in the maximum hardness achievable. ${ }^{5)}$ Trace additions of $\mathrm{Ag}$ to non-heat treatable Al-Mg alloys possess perhaps the most promising prospect for introducing or enhancing an age-hardening response. The first recorded $^{6)}$ experimental work on Agmodified alloys was to explore the effects of microalloying additions of $\mathrm{Ag}$ to $\mathrm{Al}-5$ mass\% $\mathrm{Mg}$ alloys in which it was commonly accepted that there was little or no age-hardening response. In broad terms, the effect of adding Ag was to

\footnotetext{
* Graduate Student, Monash University,
}

Present address: Department of Mechanical Engineering, College of Industrial Technology, Nihon University, Narashino 275-8575 Japan.

Corresponding author, E-mail: kubota@cit.nihon-u.ac.jp induce a significant ageing response where none existed in the binary alloy. In the case of alloys of higher $\mathrm{Mg}$ content, e.g. 10 mass $\% \mathrm{Mg}$, the very modest age-hardening response of the binary alloys was remarkably improved by microalloying additions of Ag. ${ }^{7-11)}$

Cold work, post solution treatment and prior to ageing (T8 temper), is generally known to enhance precipitation behaviour in the most age-hardenable $\mathrm{Al}$ alloys, especially the $\mathrm{Al}-$ $\mathrm{Cu}$ and $\mathrm{Al}-\mathrm{Cu}-\mathrm{Mg}$ based alloys. ${ }^{12)}$ This is because cold work introduces additional dislocations to the supersaturated solid solution and thus provides preferred heterogeneous nucleation sites for certain precipitate phases. The process has been commercially utilised application in industrial processing as a tool in thermomechanical treatment. The effect of cold working on the ageing behaviour of an Al-Mg alloy was first explored by Pollard. ${ }^{13)}$ A 5\% strain introduced to an Al10 mass $\% \mathrm{Mg}$ alloy by stretching did not stimulate its agehardening response significantly. In contrast, the effects of cold work on the ageing behaviour of an Al-8 mass\% $\mathrm{Mg}$ alloy were opposite, ${ }^{14)}$ suggesting that the hardness increases with increasing cold reduction. However, no experimental work has been reported on the effect of cold work on the precipitation hardening response in $\mathrm{Al}-\mathrm{Mg}-\mathrm{Ag}$ alloys. It is also well known that, in certain alloys, pre-existing dislocations provide preferred nucleation sites for metastable or equilibrium precipitates and that plastic deformation may thus be used to manipulate the dislocation distribution and hence the precipitate distribution. ${ }^{12)}$ It is thus very important to characterise the as-quenched microstructures, particularly with regard to the form and identity of pre-existing defects or defect clusters and their distribution.

It is the purpose of this paper to report results of a systematic investigation of the age-hardening response in Al$\mathrm{Mg}$ alloys, with and without trace additions of $\mathrm{Ag}$, aged isothermally at $160^{\circ} \mathrm{C}, 200^{\circ} \mathrm{C}$ and $240^{\circ} \mathrm{C}$. Additionally, results of a study of the effect on ageing response of cold 
work introduced after solution treatment and water quenching of ternary $\mathrm{Al}-10 \mathrm{Mg}-0.5 \mathrm{Ag}(\mathrm{mass} \%)$ alloy and prior to the ageing treatments are also presented. Analyses of the dislocation populations in the as-quenched microstructures of Al-10 mass $\% \mathrm{Mg}$ alloys with and without trace additions of $\mathrm{Ag}$ are also presented.

\section{Experimental Procedures}

\subsection{Material preparation}

Alloy ingots of the nominal compositions Al-10 mass\% $\mathrm{Mg}$ with and without 0.5 mass\% $\mathrm{Ag}$ were prepared by induction melting in high purity alumina crucibles in a conventional muffle furnace under air using elemental components of high purity (i.e. $99.99 \% \mathrm{Al}, 99.9 \% \mathrm{Mg}$ and $99.9 \% \mathrm{Ag}$ ). The molten metals were stirred mechanically and then chill-cast into cast-iron moulds with dimensions of $110 \mathrm{~mm} \times 60 \mathrm{~mm} \times 15 \mathrm{~mm}$. After these ingots were homogenised for $52 \mathrm{~h}$ at $350^{\circ} \mathrm{C}$, the surfaces on each side were scalped by milling. These ingots were then hot rolled to plate or sheet, approximately $50 \mathrm{~mm}$ thick for hardness test specimens and approximately $0.3 \mathrm{~mm}$ thick for TEM specimens. All specimens were solution treated $1 \mathrm{~h}$ at $500^{\circ} \mathrm{C}$ $\left( \pm 1^{\circ} \mathrm{C}\right)$ in a salt bath, water quenched and then aged isothermally at $160^{\circ} \mathrm{C}, 200^{\circ} \mathrm{C}$ and $240^{\circ} \mathrm{C}\left( \pm 2^{\circ} \mathrm{C}\right)$ for various times up to $2400 \mathrm{~h}$ in oil baths or salt baths.

\subsection{Hardness testing}

To assess the age-hardening response of these alloys, the bulk hardness of $50 \mathrm{~mm}$ thick samples was measured as a function of thermal treatment using a Vickers hardness tester at a load of $5 \mathrm{~kg}$. Eight indents were made for each sample, and then the maximum and minimum hardness values were discarded to calculate the average hardness from the remaining six measurements. In the case of hardness testing of samples subjected to cold work, a 7\% reduction by a single pass rolling was immediately given after water quenching and prior to ageing. To ensure uniform deformation, a small roll diameter $(70 \mathrm{~mm})$ was selected and thin, flat specimens were used. Thus the ratio of contact length to specimen thickness was approximately equal to or greater than unity, in the manner descried by Hirsch and Lücke. ${ }^{15)}$

\subsection{Microstructural observation}

All specimens for transmission electron microscopy (TEM) were punched mechanically as discs of $3 \mathrm{~mm}$ diameter from the strips of $0.3 \mathrm{~mm}$ thickness after appropriate heat treatment. They were then dry ground to a thickness of 0.1 to $0.15 \mathrm{~mm}$. These disc samples were then thinned to perforate by a twin-jet electropolishing technique. The electrolyte used was either a solution of $33 \mathrm{vol} \% \mathrm{HNO}_{3}$ and $67 \mathrm{vol} \% \mathrm{C}_{2} \mathrm{H}_{5} \mathrm{OH}$ or a solution of $33 \mathrm{vol} \% \mathrm{HNO}_{3}$ and $67 \mathrm{vol} \% \mathrm{CH}_{3} \mathrm{OH}$. Polishing was carried out in the temperature range -15 to $0^{\circ} \mathrm{C}$, using a Struers Tenupol-3 twin-jet electropolisher operating at approximately $0.2 \mathrm{~A}$ and $12 \mathrm{~V}$. Microstructures were observed using either a Philips EM420 or a CM20 transmission electron microscope (TEM) operating at $120 \mathrm{kV}$ and $200 \mathrm{kV}$, respectively.

\subsection{Dislocation analysis}

The nature, distribution and densities of dislocations in the as-quenched microstructures in alloys with and without trace additions of Ag were observed using a combination of twobeam bright field (BF) and centred-dark field imaging (CDF) techniques with several different operating diffraction vectors $g$. A method of estimating dislocation density by Bailey and Hirsch ${ }^{16)}$ has been adopted for the as-quenched microstructures in this work. In this method, dislocation density is deduced from determination of Burgers vectors, and measurements of the length of dislocation line and local foil thickness. The determination of the Burgers vector of perfect dislocations in fcc metals was based on the well-known extinction rule. ${ }^{17,18)}$ This rule is that if the dot product $\boldsymbol{g} \cdot \boldsymbol{b}$ (where $g$ is the diffraction vector for the beam used to image the dislocation, and $\boldsymbol{b}$ is the dislocation Burgers vector) is zero, the dislocation is invisible in $\mathrm{BF}$ and $\mathrm{CDF}$ images. Assuming that the dislocation segments are randomly oriented, the mean length of dislocation line, $R$, can be derived from the projected length, $R p$, using following eq. (1):

$$
R=4 R p / \pi \text {. }
$$

The local foil thickness of the TEM samples was estimated using the two-beam convergent beam electron diffraction (CBED) method which is straightforward and gives high accuracy. ${ }^{19)}$ The number density of dislocations $\rho$ in a given area $A$ on a negative micrograph was thus determined using eq. (2):

$$
\rho=R /(A t) M,
$$

where $t$ is the local foil thickness and $M$ is magnification.

\section{Experimental Results and Discussion}

\subsection{Precipitation hardening response}

Figure 1 shows the hardness curves for the $\mathrm{Al}-$ $5 \mathrm{Mg}(-0.5 \mathrm{Ag})($ mass $\%)$ alloys aged isothermally at $200^{\circ} \mathrm{C}$ and $240^{\circ} \mathrm{C}$. There is little or no hardening detectable in the binary alloy aged at $200^{\circ} \mathrm{C}$. However, the ageing response of the binary alloy is significantly enhanced by trace additions of $\mathrm{Ag}$, with peak hardness values of $\sim 85 \mathrm{VHN}$ and $\sim 65 \mathrm{VHN}$ achieved after $5 \mathrm{~h}$ at $200^{\circ} \mathrm{C}$ and $0.8 \mathrm{~h}$ at $240^{\circ} \mathrm{C}$, respectively.

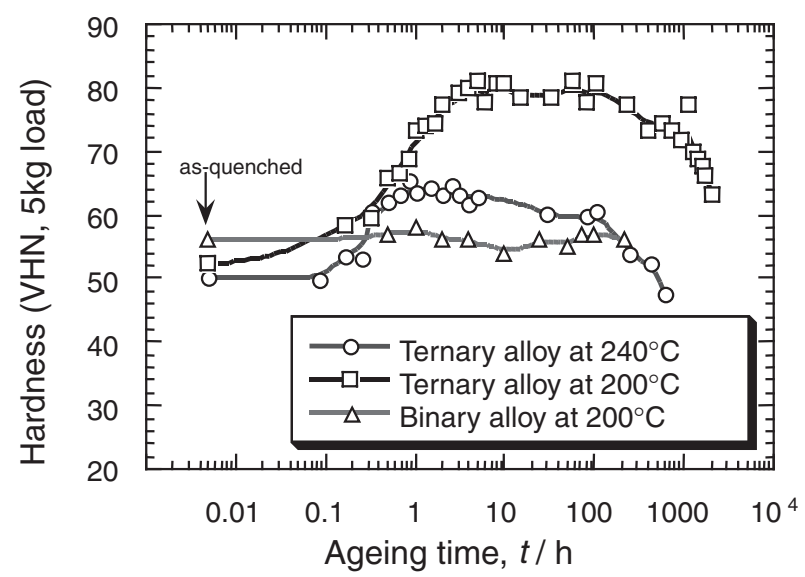

Fig. 1 Isothermal age-hardening response of $\mathrm{Al}-5 \mathrm{Mg}$ alloys, with and without trace additions of $0.5 \mathrm{Ag}$, at $200^{\circ} \mathrm{C}$ and $240^{\circ} \mathrm{C}$. 


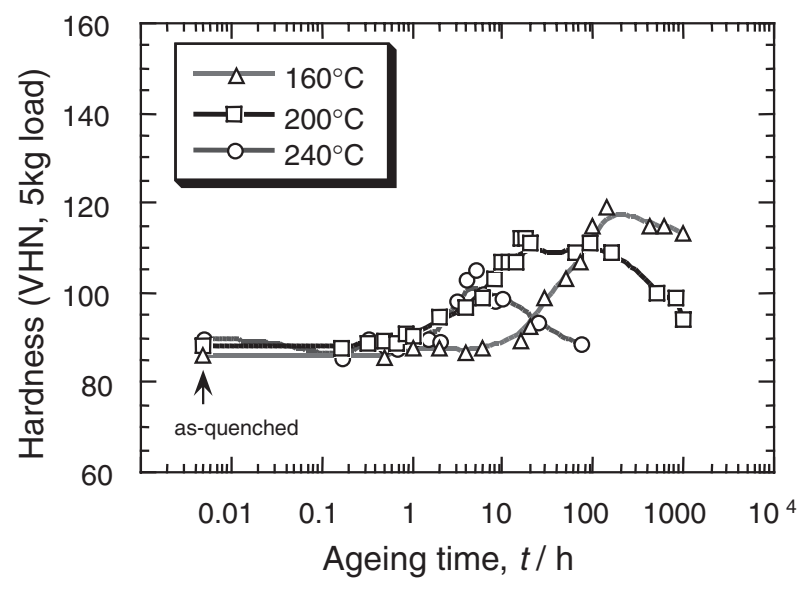

Fig. 2 Ageing curves for binary Al-10Mg alloy aged at $160^{\circ} \mathrm{C}, 200^{\circ} \mathrm{C}$ and $240^{\circ} \mathrm{C}$.

It is interesting to note that the ternary alloy, aged at both $200^{\circ} \mathrm{C}$ and $240^{\circ} \mathrm{C}$, exhibits a broad hardness plateau at maximum hardness followed by a relatively rapid decline in hardness after $\sim 100 \mathrm{~h}$, suggesting that the precipitate particles present are relatively thermally stable or that there is perhaps a sequence of precipitation reactions sustaining constant maximum hardness.

The ageing curves for binary $\mathrm{Al}-10$ mass $\% \mathrm{Mg}$ alloy aged at temperatures of $160^{\circ} \mathrm{C}, 200^{\circ} \mathrm{C}$ and $240^{\circ} \mathrm{C}$ are presented in Fig. 2. Samples of the Al-10 mass\% Mg alloy have a hardness of $\sim 90 \mathrm{VHN}$ in the as-quenched condition. At all three temperatures, there is an incubation period in excess of $1 \mathrm{~h}$ before the hardness increases gradually to maximum values of $\sim 119 \mathrm{VHN}, \sim 112 \mathrm{VHN}$ and $\sim 105 \mathrm{VHN}$ after ageing for $140 \mathrm{~h}, 16 \mathrm{~h}$ and $5 \mathrm{~h}$ at $160^{\circ} \mathrm{C}, 200^{\circ} \mathrm{C}$ and $240^{\circ} \mathrm{C}$, respectively. The behaviour is quite normal because as ageing temperature decreases from 240 to $160^{\circ} \mathrm{C}$, the maximum hardness value increases, while the time required to achieve maximum hardness increases. The precipitation response is thus accelerated by an increase in ageing temperature. The asquenched hardness of the Al-10 mass\% Mg alloy ( 90VHN) is significantly higher than that of the binary Al-5 mass\% $\mathrm{Mg}$ alloy ( $\sim 56 \mathrm{VHN})$ (Fig. 1), reflecting the substantially higher concentration of solute $\mathrm{Mg}$ retained in the solid solution.

Figure 3 illustrates the age-hardening response of ternary $\mathrm{Al}-10 \mathrm{Mg}-0.5 \mathrm{Ag}$ (mass\%) alloys aged at $160^{\circ} \mathrm{C}, 200^{\circ} \mathrm{C}$ and $240^{\circ} \mathrm{C}$. Because errors of measurement are typically $\pm 3 \mathrm{VHN}$, the hardness of $\sim 85 \mathrm{VHN}$ in the as-quenched condition is consistently lower than that of binary Al10 mass $\% \mathrm{Mg}$ alloy (Fig. 2). The hardness reaches maximum values of $\sim 150 \mathrm{VHN}, \sim 140 \mathrm{VHN}$ and $\sim 120 \mathrm{VHN}$ after ageing for $65 \mathrm{~h}, 10 \mathrm{~h}$ and $2 \mathrm{~h}$ at $160^{\circ} \mathrm{C}, 200^{\circ} \mathrm{C}$ and $240^{\circ} \mathrm{C}$, respectively, and then decreases quite rapidly in the overageing condition. The time required to achieve maximum hardness is decreased significantly in these alloys aged at $160^{\circ} \mathrm{C}$ as a result of the additions of trace amounts of Ag. It is noteworthy that there is evidence of two distinguishable stages in the hardening response and that this trend is more pronounced at the lower ageing temperatures. In the ageing curve at $160^{\circ} \mathrm{C}$, the ageing response of the ternary alloy is initially slow in the interval up to $10 \mathrm{~h}$ ageing, at which the

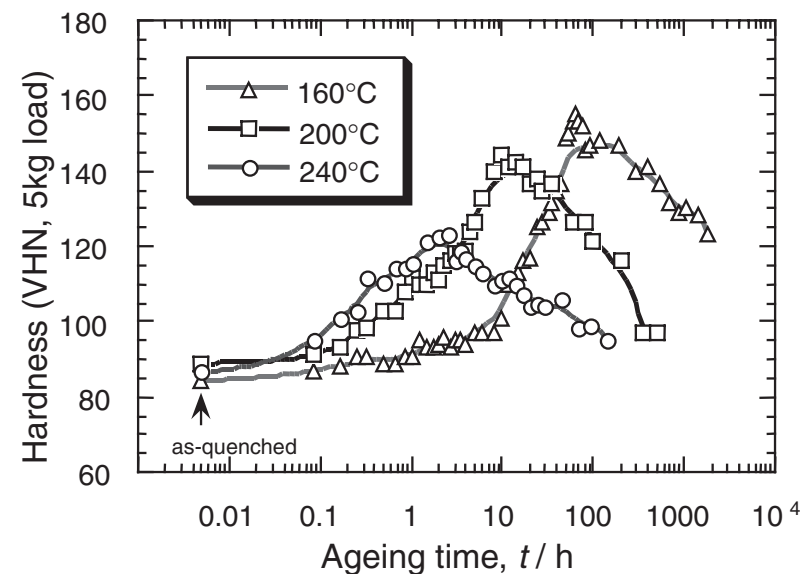

Fig. 3 Ageing curves for ternary Al-10Mg-0.5Ag alloy at ageing temperatures of $160^{\circ} \mathrm{C}, 200^{\circ} \mathrm{C}$ and $240^{\circ} \mathrm{C}$.

hardness is $\sim 100 \mathrm{VHN}$. Beyond this point, the rate of hardness increase accelerates to a maximum hardness. For the ageing curve at $200^{\circ} \mathrm{C}$, furthermore, there is again a suggestion of two distinguishable stages of the ageing response, involving an initial steady increase in hardness up to $1 \mathrm{~h}$, before a relatively sharp acceleration in the rate of age-hardening to peak hardness. Although there is similar acceleration in the rate of the age-hardening response, this trend is not so clearly observed at the ageing temperature of $240^{\circ} \mathrm{C}$.

\subsection{Effect of cold work on the hardening response}

Figure 4(a) compares the ageing curves for the T8 treatment with that for general ageing (T6 treatment) in Al$10 \mathrm{Mg}-0.5 \mathrm{Ag}$ (mass\%) alloy aged at $160^{\circ} \mathrm{C}$. In the cold worked sample, the hardness is increased significantly from $\sim 89 \mathrm{VHN}$ in the as-quenched condition to $\sim 124 \mathrm{VHN}$ after $7 \%$ cold work, due to the work hardening effect from the increased dislocation density. There is an incubation period of approximately $0.5 \mathrm{~h}$ at $160^{\circ} \mathrm{C}$ before the hardness begins to gradually increase to reach a maximum value of $\sim 167 \mathrm{VHN}$ after $8 \mathrm{~h}$. Comparing with the ageing curve for the T6 temper, the age-hardening response during the T8 temper is accelerated and the peak hardness is increased significantly in the cold worked sample. Time to reach maximum hardness $(\sim 10 \mathrm{~h})$ in the T8 condition is reduced compared to that for the T6 treatment $(\sim 100 \mathrm{~h})$, confirming that cold work stimulates precipitation through introducing a higher density of dislocations which provide preferred nucleation sites for precipitate particles.

The ageing curves for Al-10Mg-0.5Ag (mass \%) alloy aged at $200^{\circ} \mathrm{C}$, with and without $7 \%$ cold work, are presented in Fig. 4(b). The trend is similar to that observed at $160^{\circ} \mathrm{C}$. However, during ageing of the cold worked samples the hardness initially decreases to $\sim 110 \mathrm{VHN}\left(0.1 \mathrm{~h}\right.$ at $\left.200^{\circ} \mathrm{C}\right)$ before a precipitation hardening response is detectable. This initial loss of hardness is presumably due to recovery of the cold-worked samples before precipitation produces detectable hardening. Maximum hardness of $\sim 157 \mathrm{VHN}$ is achieved after $\sim 3 \mathrm{~h}$ at $200^{\circ} \mathrm{C}$ (c.f. $\sim 10 \mathrm{~h}$ in the T6 sample). During ageing, an approximately constant increment of $\sim 15 \mathrm{VHN}$ is 

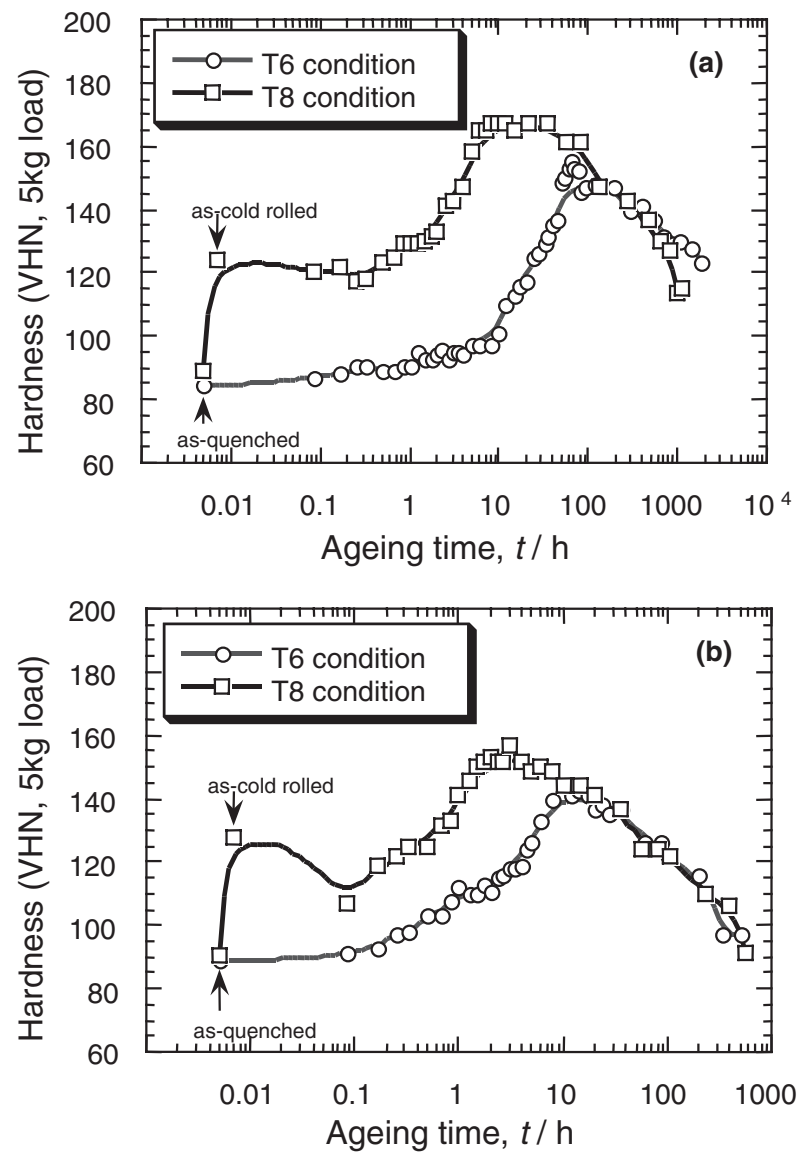

Fig. 4 Ageing curves for Al-10Mg-0.5Ag alloy with and without $7 \%$ cold work, applied post solution treatment and prior to ageing at (a) $160^{\circ} \mathrm{C}$ and (b) $200^{\circ} \mathrm{C}$.

maintained between the curves for the T6 and T8 treatments for any given ageing time up to $3 \mathrm{~h}$. Loss of hardness due to recovery of the cold worked samples is thus compensated by increased precipitation hardening and the difference in hardness is sustained until maximum hardness.

The increments in hardness between the T6 and T8 samples at maximum hardness were modest, with values of $\sim 13 \mathrm{VHN}$ and $\sim 12 \mathrm{VHN}$ for specimens aged at $160^{\circ} \mathrm{C}$ and $200^{\circ} \mathrm{C}$, respectively, suggesting that this increment is effectively independent of the ageing temperature in this range.

As in the T6 treatment, there is some evidence of two distinguishable stages of ageing response in sample exposed to the T8 treatments. This suggests that the precipitation sequence may be similar during T8 and T6 treatments, with possibly only the density of precipitate particles in the T8 samples being higher than in the T6 specimens. Alternative$1 y$, the increased hardness achieved during the T8 treatment may be attributable to the precipitate particles in the cold work specimens being much more uniformly distributed than in the undeformed specimens. Detailed microstructural evolutions corresponding to the age-hardening curves for T6 and T8 treatments in the binary and ternary alloys will be discussed elsewhere.

The effect of cold work on the age-hardening behaviour in binary Ag-free alloys has been investigated, ${ }^{14)}$ and it has been shown that the maximum hardness does not increase significantly for up to $25 \%$ cold work. However, the current results suggest that the effect of microalloying additions of Ag may be further enhanced by cold-working prior to ageing, most notably via an acceleration in the kinetics of precipitation hardening. Such an observation is significantly important if these alloys are to be considered for industrial applications where the practicality of the thermomechanical processing route is a major issue.

\subsection{Relationship between hardness and dislocation den- sity}

\subsubsection{Dislocation structures}

An interesting observation arising from the hardness measurements was that the hardness of the as-quenched samples of the Ag-modified alloys was consistently lower than that of the Ag-free binary alloys. The effect was more pronounced in the Al-5 mass \% Mg alloys, but also evident in the $\mathrm{Al}-10$ mass $\% \mathrm{Mg}$ alloys. In order to seek an explanation for this phenomenon, a study was conducted of the line defect structures in the as-quenched samples of the Al-10 mass\% $\mathrm{Mg}$ alloys with and without $0.5 \mathrm{mass} \% \mathrm{Ag}$.

Figure 5 presents TEM micrographs of typical dislocation structures in the as-quenched condition in the binary Al10 mass $\% \mathrm{Mg}$ alloy. Figures 5(a) and (b) represent centred dark field (CDF) and bright field (BF) images, respectively, with the electron beam approximately parallel to $\langle 101\rangle_{\alpha}$ direction and the selected operating $g$ vector corresponding to the $\langle 0 \overline{2} 0\rangle_{\alpha}$. Based on examination of the line directions of observed dislocations in these TEM micrographs, there are two distinguishable sets of dislocations which are visible. One set of dislocations has a projected trace parallel to $\langle\overline{1} \overline{3} 1\rangle_{\alpha}$ and the other set is parallel in projection to $\langle\overline{1} 11\rangle_{\alpha}$. Those sets of dislocations parallel to $\langle\overline{1} 31\rangle_{\alpha}$ and $\langle\overline{1} 11\rangle_{\alpha}$ are referred to as arrays A and B, respectively. Figures 5(c), (d) and (e) present $\mathrm{CDF}$ images respectively of the same field in the as-quenched microstructure in binary Al-10 mass $\% \mathrm{Mg}$ alloy. The electron beam is again near $\langle 101\rangle_{\alpha}$ and the operating $g$ vector now parallel to the $\langle 11 \overline{1}\rangle_{\alpha},\langle\overline{1} 11\rangle_{\alpha}$ and $\langle\overline{2} 02\rangle_{\alpha}$ directions, respectively. As shown in Fig. 5(c), two distinguishable sets of dislocations are now visible. The dislocations (type A) parallel to the trace of $\langle\overline{1} \overline{3} 1\rangle_{\alpha}$ remain visible, while there is a new set $C$ of dislocations parallel to the trace of $\langle\overline{2} 02\rangle_{\alpha}$. It should be noted that the set of dislocations (type B), which were visible with $\boldsymbol{g}=\langle 0 \overline{2} 0\rangle_{\alpha}$ in Fig. 5(a), are now invisible. Additionally, the array of dislocations (type $\mathrm{C}$ ) were invisible with $\boldsymbol{g}=\langle 0 \overline{2} 0\rangle_{\alpha}$ in Fig. 5(a). In Fig. 5(d), two distinguishable sets of dislocations (type $\mathrm{B}$ and $\mathrm{C}$ ) are visible. However, those with traces parallel to $\langle\overline{1} \overline{3} 1\rangle_{\alpha}$ (type A), which were visible with $\boldsymbol{g}=\langle 0 \overline{2} 0\rangle_{\alpha}$ and $\boldsymbol{g}=\langle 11 \overline{1}\rangle_{\alpha}$ in Fig. 5(a) and (c), respectively, are now invisible. With the operating $g$ vector in Fig. 5(e), all three distinguishable sets of dislocations are now visible. By careful tilting experiments of the micrographs presented above, it was confirmed that there are three distinguishable sets of dislocations, $\mathrm{A}, \mathrm{B}$ and $\mathrm{C}$ within the asquenched microstructure in the binary $\mathrm{Al}-10$ mass $\% \mathrm{Mg}$ alloy. The dislocation arrays shown in Fig. 5 were representative of the microstructure of specimens in the as-quenched condition.

Table 1 presents a summary of the crystallographic analy- 

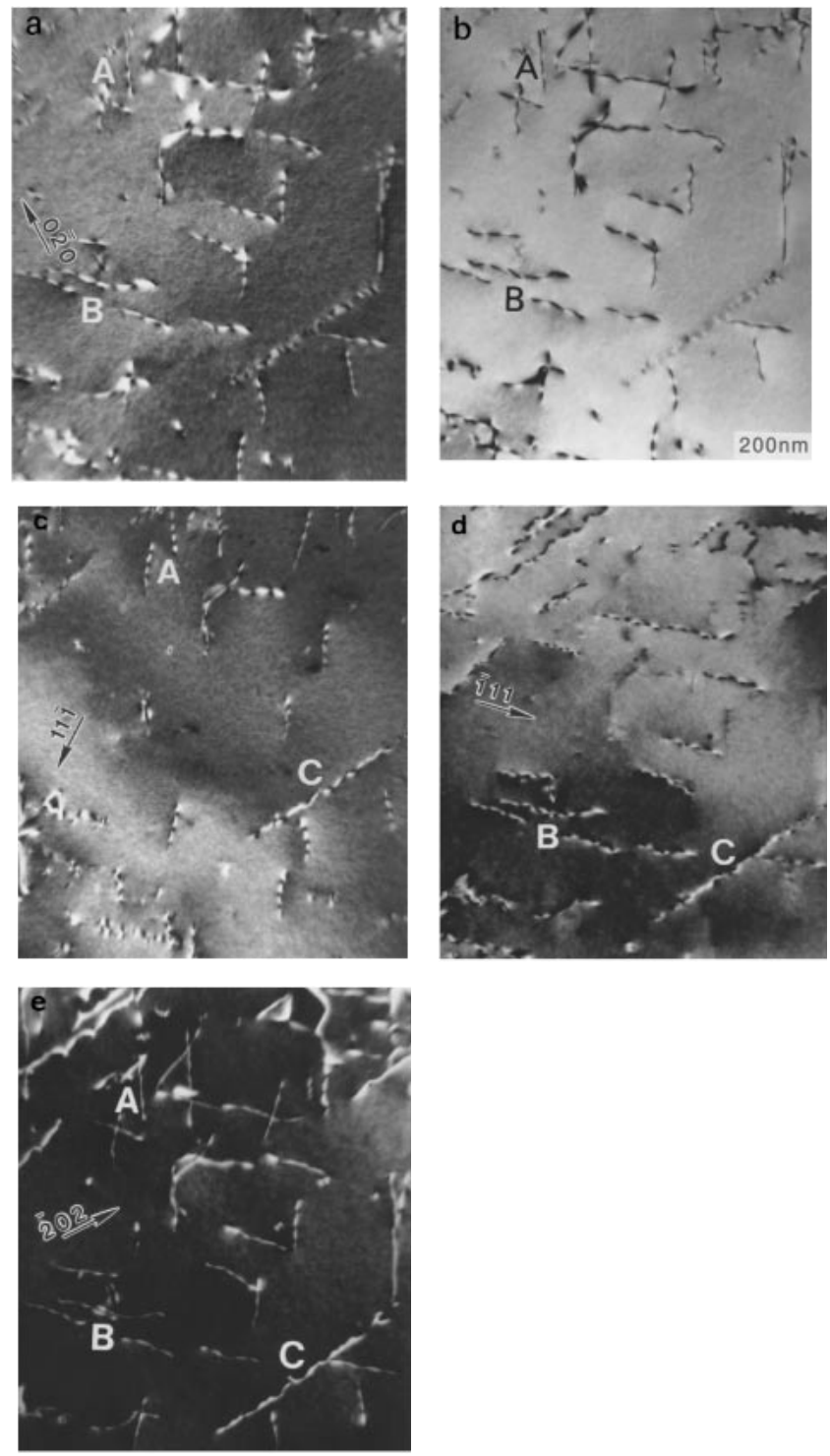

Fig. 5 TEM micrographs showing (a) CDF, (b) BF, (c), (d) and (e) CDF images of the as-quenched microstructure in Al-10Mg alloy with $\boldsymbol{B}$ approximately parallel to $\langle 101\rangle_{\alpha}$ direction and the operating $\boldsymbol{g}$ vectors parallel to: (a), (b) $\langle 0 \overline{2} 0\rangle_{\alpha}$, (c) $\langle 11 \overline{1}\rangle_{\alpha}$, (d) $\langle\overline{1} 11\rangle_{\alpha}$ and $\langle\overline{2} 02\rangle_{\alpha}$.

sis of the dislocations observed in the as-quenched microstructure of the binary Al-10 mass\% Mg alloy. The electron beam for this analysis was approximately parallel to $\langle 101\rangle_{\alpha}$, $\langle 1 \overline{1} 2\rangle_{\alpha}$ and $\langle 1 \overline{1} 1\rangle_{\alpha}$ directions. Dislocations (type A) were visible with any of the operating vectors $g$ of $\langle 11 \overline{1}\rangle,\langle 0 \overline{2} 0\rangle$, $\langle\overline{2} 02\rangle,\langle 131\rangle,\langle 220\rangle,\langle 20 \overline{2}\rangle$ and $\langle 022\rangle$, but invisible when the operating vectors $g$ were parallel to $\langle\overline{1} 11\rangle$ and $\langle 1 \overline{1} \overline{1}\rangle$. Using
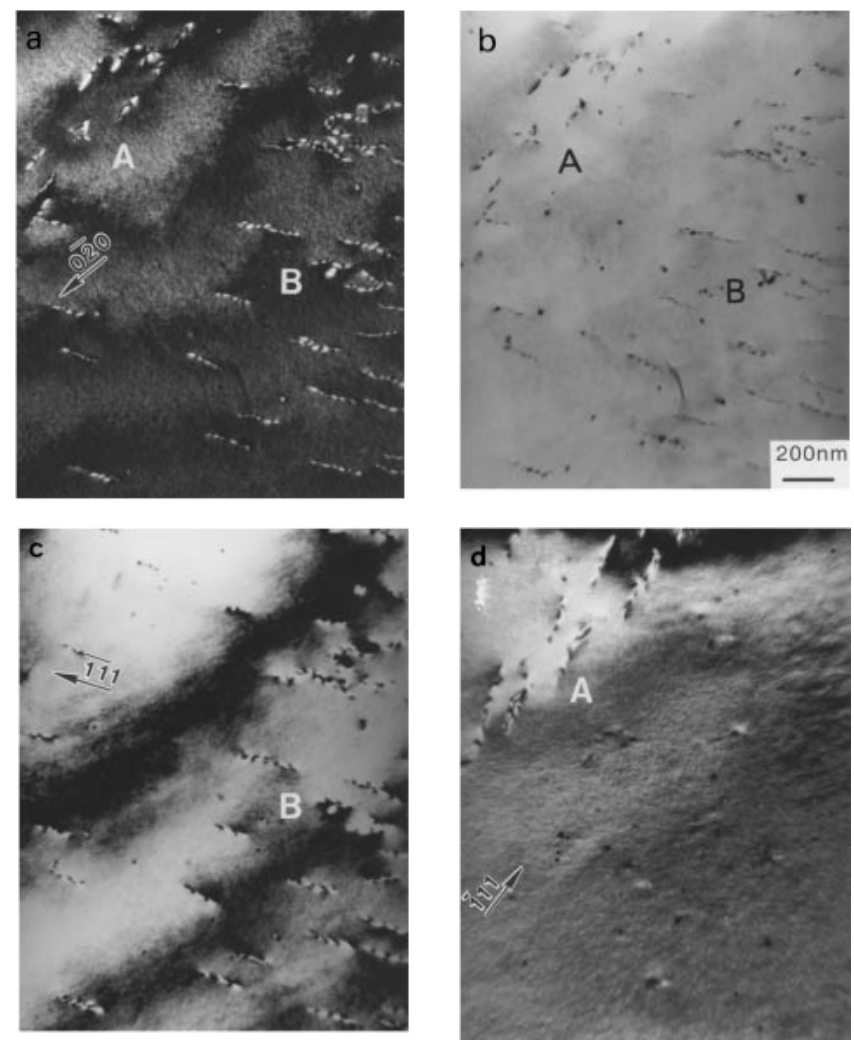

Fig. 6 TEM micrographs showing (a) CDF, (b) BF, (c) and (d) CDF images of the as-quenched microstructure in Al-10Mg- $0.5 \mathrm{Ag}$ alloy with $\boldsymbol{B}$ approximately parallel to $\langle 101\rangle_{\alpha}$ direction and the operating $\boldsymbol{g}$ vectors parallel to: (a), (b) $\langle 0 \overline{2} 0\rangle_{\alpha}$, (c) $\langle\overline{1} \overline{1} 1\rangle_{\alpha}$ and (d) $\langle\overline{1} 11\rangle_{\alpha}$.

the $\boldsymbol{g} \cdot \boldsymbol{b}=0$ invisibility criterion, the possible Burgers vectors are $\boldsymbol{b}=a / 2[110], \boldsymbol{b}=a / 2[101]$ or $\boldsymbol{b}=a / 2$ [011] . If the Burgers vector were $\boldsymbol{b}=a / 2$ [101] for dislocations (type A), then these dislocations should be invisible with $\boldsymbol{g}=\langle 0 \overline{2} 0\rangle$. However, the dislocations were visible in images with $\boldsymbol{g}=\langle 0 \overline{2} 0\rangle$, eliminating this hypothesis. Similarly, if the Burgers vector were $\boldsymbol{b}=a / 2[01 \overline{1}]$ for dislocations (type A), then they should be invisible with $g=\langle 022\rangle$, but again this did act prove to be the case. Therefore, the only consistent solution for dislocations A was found to be $\boldsymbol{b}=a / 2[110]$. The same manner as the dislocations (type A) have been applied for dislocations (type B and C) in the as-quenched sample of the Al-10 mass\% $\mathrm{Mg}$ alloy, and then the only consistent solution for dislocations (type B and C) was found to be the Burgers vector $\boldsymbol{b}=a / 2[1 \overline{1} 0]$ and $\boldsymbol{b}=a / 2[10 \overline{1}]$, respectively.

Figure 6 presents TEM micrographs of typical dislocation structures in the as-quenched condition in the ternary Al-

Table 1 Conditions of visibility for dislocations in as-quenched Al-10Mg alloy.

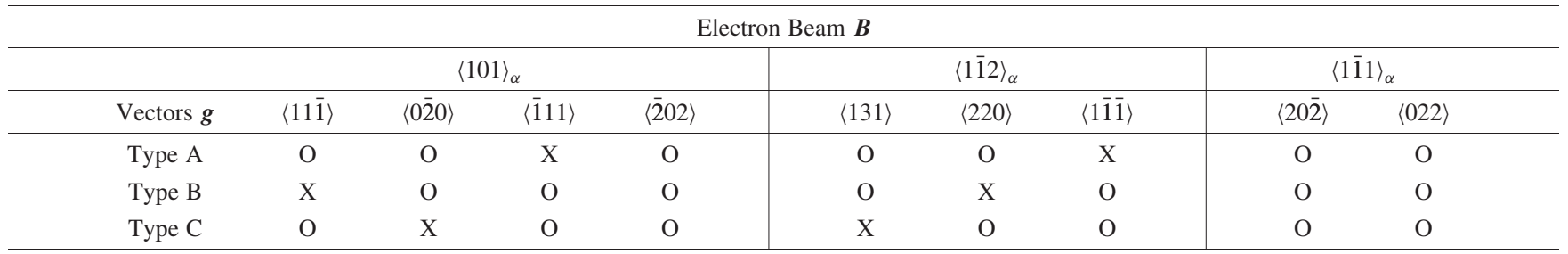

$\mathrm{O}=$ loop visible $\mathrm{X}=$ loop invisible 
Table 2 Conditions of visibility for dislocations in as-quenched $\mathrm{Al}-10 \mathrm{Mg}$ $0.5 \mathrm{Ag}$ alloy.

\begin{tabular}{cccccc|cc}
\hline \multicolumn{7}{c}{ Electron Beam $\boldsymbol{c}$} \\
\hline \multicolumn{7}{c}{$\langle 101\rangle_{\alpha}$} \\
\hline Vectors $\boldsymbol{g}$ & $\langle 020\rangle$ & $\langle 0 \overline{2} 0\rangle$ & $\langle\overline{1} \overline{1} 1\rangle$ & $\langle\overline{1} 11\rangle$ & $\langle 11 \overline{1}\rangle$ & \multicolumn{2}{c}{$\langle 001\rangle_{\alpha}$} \\
\hline Type A & O & O & X & O & X & O & O 20$\rangle$ \\
Type B & O & O & O & X & O & X & O \\
\hline
\end{tabular}

$\mathrm{O}=$ loop visible $\mathrm{X}=$ loop invisible

$10 \mathrm{Mg}-0.5 \mathrm{Ag}(\operatorname{mass} \%)$ alloy. Figures $6(\mathrm{a})$ and (b) show CDF and $\mathrm{BF}$ images, respectively. The electron beam is approximately parallel to $\langle 101\rangle_{\alpha}$ direction and the selected operating $g$ vector is $\langle 0 \overline{2} 0\rangle_{\alpha}$. There are two distinguishable sets of dislocations, which are visible. These sets of dislocations have a projected trace parallel to $\langle\overline{1} 31\rangle_{\alpha}$ and $\langle\overline{1} \overline{1} 1\rangle_{\alpha}$ referred to as arrays A and B, respectively. Figures 6(c) and (d) show $\mathrm{CDF}$ images of the same field in the as-quenched microstructure in ternary $\mathrm{Al}-10 \mathrm{Mg}-0.5 \mathrm{Ag}$ (mass\%) alloy. The electron beam is again near $\langle 101\rangle_{\alpha}$ and the operating $\boldsymbol{g}$ vector now parallel to the $\langle\overline{1} \overline{1} 1\rangle_{\alpha}$ and $\langle\overline{1} 11\rangle_{\alpha}$ directions. In Fig. 6(c), only one set of dislocations (type B) is now visible, whereas with the operating $g$ vector in Fig. 6(d), only one set of dislocations (type A) is now visible. After careful tilting experiments of the micrographs presented above, it was confirmed that there are typically two distinguishable sets of dislocations, $\mathrm{A}$ and $\mathrm{B}$, within representative of the asquenched microstructure at random locations within specimens in the ternary $\mathrm{Al}-10 \mathrm{Mg}-0.5 \mathrm{Ag}$ (mass\%) alloy.

Table 2 shows a summary of the crystallographic analysis of the dislocations observed in the as-quenched microstructure of the ternary $\mathrm{Al}-10 \mathrm{Mg}-0.5 \mathrm{Ag}$ (mass\%) alloy. The electron beam for this analysis was approximately parallel to $\langle 101\rangle_{\alpha}$ and $\langle 001\rangle_{\alpha}$ directions. Applying the same analyses as the dislocations in the binary $\mathrm{Al}-10$ mass $\% \mathrm{Mg}$ alloy to dislocations in the ternary $\mathrm{Al}-10 \mathrm{Mg}-0.5 \mathrm{Ag}$ (mass\%) alloys, the only consistent solution for dislocations (type A and B) was found to be the Burgers vector $\boldsymbol{b}=a / 2[1 \overline{1} 0]$ and $\boldsymbol{b}=a / 2[01 \overline{1}]$, respectively.

The identity of the dislocations in the as-quenched microstructures of the binary $\mathrm{Al}-10 \mathrm{Mg}$ and ternary $\mathrm{Al}$ $10 \mathrm{Mg}-0.5 \mathrm{Ag}$ (mass\%) alloys was found to be the same; i.e. in both alloys all dislocations were unit perfect dislocations with Burgers vectors of the form $a / 2\langle 110\rangle$. This result suggests that trace additions of Ag to binary Al-10 mass\% $\mathrm{Mg}$ alloy have no effect on changing the identity of the dislocations. There was no evidence of dissociation of the $a / 2\langle 110\rangle$ dislocations in either alloy as-quenched.

\subsubsection{Measurement of length of dislocation lines}

The total projected length of observed dislocations in a thin foil sample, $R p$, was measured from CDF and BF image negatives, with the selected operating $\boldsymbol{g}$ vectors being $\langle\overline{2} 02\rangle_{\alpha}$ and $\langle 0 \overline{2} 0\rangle_{\alpha}$ for the binary and ternary alloys, respectively. Both $g$ vectors allow that all possible existing dislocations are visible simultaneously as summarised in Tables 1 and 2 . Measured total projected length of dislocations, $R p$, in the binary alloy was more than twice that measured in the ternary alloy, as presented in Table 3. The errors in $R p$ shown in Table 3 were calculated on the assumption that the length of
Table 3 Measurement of dislocation line length in Al-10Mg and Al-10Mg$0.5 \mathrm{Ag}$ alloys.

\begin{tabular}{ccc}
\hline Alloy & Al-10Mg & Al-10Mg-0.5Ag \\
\hline$R p$ & $64.92 \pm 0.61 \mathrm{~cm}$ & $29.83 \pm 0.25 \mathrm{~cm}$ \\
$R$ & $82.66 \pm 0.78 \mathrm{~cm}$ & $37.98 \pm 0.32 \mathrm{~cm}$ \\
$A$ & $9.75 \times 8.10=78.975 \mathrm{~cm}^{2}$ & $9.80 \times 7.90=77.420 \mathrm{~cm}^{2}$ \\
\hline
\end{tabular}

each projected segment of dislocation line could be measured accurately to within $\pm 0.01 \mathrm{~cm}$. In the case of Al-10 mass $\%$ $\mathrm{Mg}$ alloy, for example, there were 61 separate segments of dislocation line and the total error was thus of the order of $\pm 0.61 \mathrm{~cm}$.

\subsubsection{Measurement of foil thickness}

The local foil thickness of the TEM samples was estimated using the two-beam convergent beam electron diffraction (CBED) method. ${ }^{19)}$ Figure 7 shows typical examples of CBED patterns recorded from (a) Al-10Mg and (b) Al-10Mg$0.5 \mathrm{Ag}(\operatorname{mass} \%)$ alloys in the as-quenched condition. The two beam condition was selected with the electron beam parallel to $\langle 110\rangle_{\alpha}$ and an operating vector $\boldsymbol{g}=220$. The values of $S_{i}$ are determined by measuring the distance $\Delta \theta_{i}$ from the centre of the diffracted beam profile to each of the successive minima, together with the distance $2 \theta_{d}$ between the centre spot and the diffracted spot as shown in the following eq. (3):
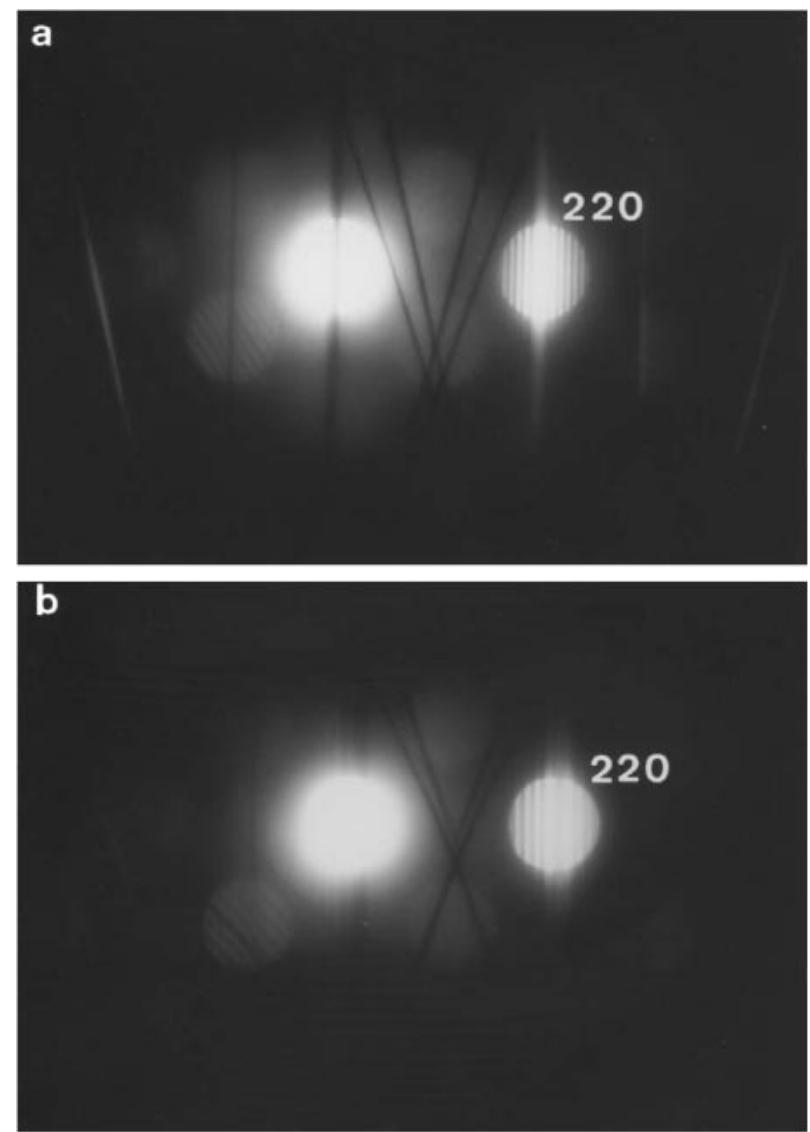

Fig. 7 Two-beam CBED patterns recorded from (a) Al-10Mg and (b) Al$10 \mathrm{Mg}-0.5 \mathrm{Ag}$ alloys in the as-quenched condition for foil thickness determination. The two beam condition is such that $g=220$ is the operating vector at $120 \mathrm{kV}$. 
Table 4 Measurement of pattern parameters and foil thickness in Al-10Mg and Al-10Mg-0.5 Ag alloys.

\begin{tabular}{cccccccc}
\hline No. & $\begin{array}{c}2 \theta_{d} \\
(\mathrm{~mm})\end{array}$ & $\begin{array}{c}\Delta \theta_{1} \\
(\mathrm{~mm})\end{array}$ & $\begin{array}{c}\Delta \theta_{2} \\
(\mathrm{~mm})\end{array}$ & $\begin{array}{c}\Delta \theta_{3} \\
(\mathrm{~mm})\end{array}$ & $\begin{array}{c}\Delta \theta_{4} \\
(\mathrm{~mm})\end{array}$ & $\begin{array}{c}R \\
(\mathrm{~mm})\end{array}$ & $\begin{array}{c}\text { Thickness } \\
(\mathrm{nm})\end{array}$ \\
\hline Al-10Mg & 10.9 & 1.0 & 1.9 & 2.7 & 3.5 & 4.8 \\
Al-10Mg-0.5Ag & 10.9 & 1.8 & 2.3 & 3.8 & - & 4.8 \\
\hline
\end{tabular}

Table 5 Comparison of dislocation densities for $\mathrm{Al}-10 \mathrm{Mg}$ and $\mathrm{Al}-10 \mathrm{Mg}$ $0.5 \mathrm{Ag}$ alloys.

\begin{tabular}{ccc}
\hline $\begin{array}{c}\text { Alloy } \\
(\text { mass })\end{array}$ & Al-10Mg & Al-10Mg-0.5Ag \\
\hline $\begin{array}{c}\text { Foil Thickness, } \\
t(\mathrm{~nm})\end{array}$ & $75.0 \pm 1.5$ & $63.3 \pm 1.3$ \\
$\begin{array}{c}\text { Magnification } \\
\text { Dislocation Density } \\
\rho\left(\mathrm{cm}^{-2}\right)\end{array}$ & $36300 \times$ & $36300 \times$ \\
\hline
\end{tabular}

$$
S_{i}=\frac{\lambda}{d^{2}}\left(\frac{\Delta \theta_{i}}{2 \theta_{d}}\right)
$$

where $\lambda$ is the wavelength and $d$ is the spacing of the planes giving rise to the operating reflection. With an operating accelerate voltage at $120 \mathrm{kV}$, the values of the required parameters were as follows: $\lambda=0.00335 \mathrm{~nm}$, lattice constant of $\mathrm{Al} ; a=0.405 \mathrm{~nm}, \boldsymbol{g}=220$. From these parameters $S_{i}$ can be obtained. Results of the thickness determination are shown in Table 4. The errors in foil thickness were analysed by the repeated measurements of the fringes in the diffraction discs in the same negatives, and estimated to be approximately $\pm 2 \%$. Therefore, foil thickness for the binary Al-10 mass $\%$ $\mathrm{Mg}$ alloy was $75.0 \pm 1.5 \mathrm{~nm}$, and for the ternary $\mathrm{Al}-10 \mathrm{Mg}$ $0.5 \mathrm{Ag}$ (mass\%) alloy was $63.3 \pm 1.3 \mathrm{~nm}$.

\subsubsection{Determination of dislocation density}

Dislocation density is defined as the measured total dislocation line length in a unit volume of crystal, giving a parameter with dimensions $\mathrm{cm} / \mathrm{cm}^{3}$ or $\mathrm{cm}^{-2}$. Table 5 compares the dislocation densities calculated for the binary $\mathrm{Al}-10 \mathrm{Mg}$ and ternary $\mathrm{Al}-10 \mathrm{Mg}-0.5 \mathrm{Ag}$ (mass\%) alloys, and shows that density in the binary alloy is almost twice that in the ternary alloy. Bailey and Hirsch ${ }^{16)}$ have suggested that this method of estimating the density of dislocations may involve errors of up to $\pm 25 \%$. In addition, the foil thickness cannot be claimed to be accurate to better than $\pm 2 \% .{ }^{19)}$ However, even allowing for such errors, it is clear that the dislocation density in the ternary Ag-modified alloy is significantly lower than that in the binary alloy. This is consistent with the proposal that the addition of $\mathrm{Ag}$ will lead to a reduction in the as-quenched dislocation density.

The precise role of Ag has not been verified directly, but it is commonly suggested that, because of the high binding energy between $\mathrm{Ag}$ atoms and vacancies, ${ }^{20)}$ the $\mathrm{Ag}$ atoms present trap vacancies and reduce the number of vacancies that condense and collapse to form dislocation loops. Additionally, the $\mathrm{Mg}$ and $\mathrm{Ag}$ atoms have a strong tendency to interact with each other because the Ag-Mg pair has a negative excess enthalpy value, while the interaction between solute atoms and quenched-in vacancies is stronger for $\mathrm{Mg}$ atoms than for $\mathrm{Ag}$ atoms. ${ }^{20)}$ This implies that a lower number density of dislocations is to be expected in Al-Mg-Ag ternary alloys compared with that in Al-Mg binary alloys of similar composition.

\subsubsection{Relationship between hardness and dislocation density}

In order to examine the relationship between the hardness and the number density of dislocations in the as-quenched state, theoretical calculation of shear stress $\tau$ was carried out using an equation of the form: ${ }^{21)}$

$$
\tau=\alpha \mu \boldsymbol{b} \rho^{0.5},
$$

where $\boldsymbol{b}$ is the Burgers vector, $\rho$ is the dislocation density, $\tau$ is shear strength, $\mu$ is the shear modulus and $\alpha$ is a geometric constant. Hansen ${ }^{22)}$ obtained a value for $\alpha$ of 0.2 for aluminium alloys, while from TEM observations in the current research, the dislocation densities in the as-quenched condition were $5.1 \times 10^{9} \mathrm{~cm}^{-2}$ for the binary Al-10 mass $\%$ $\mathrm{Mg}$ alloy and $2.8 \times 10^{9} \mathrm{~cm}^{-2}$ for the ternary Al-10Mg- $0.5 \mathrm{Ag}$ (mass\%) alloy. In the case of the aluminium alloy, $\boldsymbol{b}$ is $2.86 \times 10^{-10} \mathrm{~m}$ and $\mu$ is $25 \mathrm{GPa}^{2)}$ Using these parameters, the values of shear yield strength were calculated to be 10.2 MPa and 7.6 MPa for the Al-10Mg and Al-10Mg-0.5Ag (mass\%) alloys, respectively. The relationship between tensile stress $(\sigma)$ and shear stress $(\tau)$ is commonly assumed to be of the form $\sigma=A \tau{ }^{21)}$ where $A$ is the Taylor factor. The Taylor factor for fcc materials is approximately $3.067,{ }^{22)}$ and the values of tensile yield stress derived from the above values of shear stress were thus $31.3 \mathrm{MPa}$ and $23.3 \mathrm{MPa}$ for the $\mathrm{Al}-10 \mathrm{Mg}$ and $\mathrm{Al}-10 \mathrm{Mg}-0.5 \mathrm{Ag}$ (mass\%) alloys, respectively. Given that it is also commonly accepted that the relationship between tensile yield stress and Vickers hardness (VHN) is at least approximately of the form $\sigma=3 \times \mathrm{VHN}$. It is thus to be expected that on the basis of differences in dislocation density alone, the hardness values for the binary and ternary alloys would be expected to differ by a factor of $\left(\rho_{B} \rho_{T}\right)^{0.5}=(5.1 / 2.8)^{0.5}=1.35$. Allowing for errors of $\pm 25 \%$ on the measurements of $\rho$ and taking the worst possible combination of errors, this ratio might be reduced to a value of 1.09. From the measurements of bulk Vickers hardness (Fig. 1 to 3), experimental values of the ratio of asquenched hardness in the binary alloys to that in the ternary alloys were of the order of 1.12 and 1.06 for the Al-5Mg and $\mathrm{Al}-10 \mathrm{Mg}$ (mass\%) alloys, respectively. Thus, even allowing for substantial experimental errors in the determination of dislocation densities $(\rho)$, it is clear that the measured differences in $\rho$ are sufficient to account for the measured differences in as-quenched hardness between the Ag-free and Ag-modified alloys.

\section{Conclusions}

Based on the measurements of hardness and analyses of the as-quenched microstructures of Al-Mg alloys with and 
without 0.5 mass $\% \mathrm{Ag}$, the principal results are summarised as follows:

(1) There is no detectable age-hardening response in solution treated and quenched $\mathrm{Al}-5$ mass $\% \mathrm{Mg}$ alloy aged at $200^{\circ} \mathrm{C}$. However, an increase in solute $\mathrm{Mg}$ content does lead to a modest precipitation hardening response in supersaturated $\mathrm{Al}-10$ mass $\% \mathrm{Mg}$ alloy aged at $160^{\circ} \mathrm{C}, 200^{\circ} \mathrm{C}$ and $240^{\circ} \mathrm{C}$.

(2) Trace additions ( 0.5 mass $\%$ ) of $\mathrm{Ag}$ to $\mathrm{Al}-\mathrm{Mg}$ alloys with low solute $\mathrm{Mg}$ contents ( $<5$ mass $\%$ ) promote an age-hardening response, while similar additions to $\mathrm{Al}-\mathrm{Mg}$ alloys with higher solute $\mathrm{Mg}$ contents enhance significantly the agehardening response. In the latter alloy, the addition of $\mathrm{Ag}$ leads to both an acceleration of the precipitation hardening process and an increase in maximum hardness.

(3) The age-hardening response in an Al-10Mg-0.5 Ag (mass\%) alloy may be significantly enhanced by the introduction of $7 \%$ cold work, post solution treatment and prior to ageing at $160^{\circ} \mathrm{C}$ and $200^{\circ} \mathrm{C}$. The ageing behaviour is further accelerated and a modest increase $(\sim 12 \mathrm{VHN})$ in maximum hardness is obtained.

(4) The identity of the dislocations in as-quenched Ag-free and Ag-modified Al-10 mass $\% \mathrm{Mg}$ alloys has been confirmed as unit perfect $a / 2\langle 110\rangle$ type. The addition of $\mathrm{Ag}$ does not appear to modify the form of the dislocations and no dissociation of these dislocations was observed in this condition.

(5) The density of dislocations in the solution treated and quenched condition in the Al-10 mass \% Mg alloy was higher by a factor of $\sim 2$ than that in $\mathrm{Al}-10 \mathrm{Mg}-0.5 \mathrm{Ag}$ (mass \%) alloy subjected to similar treatment. This difference is sufficient to account for the higher hardness observed in the as-quenched binary alloy than that in the ternary alloy. The decreased density of dislocations in the Ag-modified alloy is attributed to an interaction between $\mathrm{Ag}$ atoms and vacancies which reduces the vacancy population available to condense and collapse to form dislocation loops.

\section{Acknowledgments}

This research was supported by the Australian Research
Council. The useful discussion from Emeritus Professor I. J. Polmear greatly acknowledged. One of the authors (M.K.) acknowledges gratefully the support of a Monash Graduate Scholarship (MGS) from Monash University and an Overseas Postgraduate Research Scholarship (OPRS) from the Commonwealth Department of Employment, Education and Training (DEET), Australian government.

\section{REFERENCES}

1) I. J. Polmear: Light Alloys; Metallurgy of the Light Metals, 3rd edition, (Arnold, London, 1995).

2) L. F. Mondolfo: Structure and properties, 1st edition, (Butterworths, London, 1976) 312.

3) E. C. W. Perryman and G. B. Brook: J. Inst. Metals 79 (1951) 19-34.

4) I. J. Polmear: Trans. Metall. Soc. AIME 230 (1964) 1331-1339.

5) I. J. Polmear: J. Metals 20 (1968) 44-51.

6) I. J. Polmear and K. R. Sargant: Nature 200 (1963) 669-670.

7) Y. Baba: Trans. JIM 13 (1972) 76-81.

8) F. J. Kievits and A. J. Zuithoff: J. Inst. Metals 93 (1965) 517-519.

9) T. Ito, K. Matsuura and K. Watanabe: J. Japan Inst. Metals 33 (1969) 1227-1232.

10) T. Ito, T. Furuya, K. Matsuura and K. Watanabe: Trans. JIM 12 (1971) 379-385.

11) T. Takahashi, Y. Kojima and S. Okaniwa: J. Japan Inst. Metals 42 (1978) 396-402.

12) A. Kelly and R. B. Nicholson: Prog. Mater. Sci. 10 (1963) 149-392.

13) W. A. Pollard: J. Inst. Metals 93 (1965) 339-346.

14) B. Cottereau, G. Itoh and M. Kanno: J. Japan Inst. Metals 53 (1989) 157-163.

15) J. Hirsch and K. Lücke: Acta Metall. 36 (1988) 2863-2882.

16) J. E. Bailey and P. B. Hirsch: Philos. Mag. 5 (1960) 485-497.

17) J. W. Edington: Practical Electron Microscopy in Materials Science, Vol. 3, (Macmillian, London, 1976) 107.

18) D. B. Williams and C. B. Carter: Transmission Electron Microscopy - A Textbook for Materials Science, (Plenum Press, New York, 1996) Chapter 25.

19) P. M. Kelly, A. Jostsons, R. G. Blake and J. P. Napier: Phys. Status Solidi (a) 31 (1975) 771-780.

20) B.-P. Huang and Z.-Q. Zheng: Acta Mater. 46 (1998) 4381-4393.

21) G. E. Dieter: Mechanical Metallurgy, 2nd edition, (McGraw-Hill, London 1988) 143.

22) N. Hansen: Acta Metall. 25 (1977) 863-869. 